\title{
Answer to head and neck imaging
}

Author:

Shalen Misser ${ }^{1}$

\section{Affiliation:}

${ }^{1}$ Lake Smit and Partners Inc.

Durban, South Africa

\section{Correspondence to:}

Shalen Misser

Email:

misser@lakesmit.co.za

\section{Postal address:}

Private Bag X08, Overport 4067, Durban, South Africa

How to cite this article: Misser. S. Answer to head and neck imaging. S Afr J Rad. 2014;18(1); Art. \#705 3 pages. http://dx.doi/ org/10.4102/sajr.v18i1.705

\section{Copyright:}

(c) 2014. The Authors. Licensee: AOSIS

OpenJournals. This work

is licensed under the

Creative Commons

Attribution License.

Several answers to the quiz question were received from all quarters of the country. Noteworthy responses came from Drs Ian Haynes, Nikelo Mabandla, Francois Roux, Mlindeli Masango, Andrew Lawson, Zakariya Vawda and Zain Ally. Spot-on diagnoses with the best radiological descriptions obtained were from Dr Naye Sihlali and Dr Fourie Bezuidenhout, who share the prize. Congratulations to all respondents.

\section{Presentation}

A 26-year-old woman presented with a painful paramedian anterior neck mass. Her ultrasound and computerised tomography (CT) images appear below.

\section{Findings and diagnosis}

The ultrasound image (Figure 1) shows a right para-median anterior neck mass of mixed echogenicity measuring $2.3 \mathrm{~cm} \times 1.9 \mathrm{~cm}$, including a predominant cystic component and an internal microlobulated papillary projection containing calcification. The computerised tomography (CT) image (Figure 2) at the level of the hyoid bone demonstrates the anterior neck cystic mass with an internal solid and calcific component. Figure 3 is a sagittal CT reformat demonstrating the cyst just inferior to the submental space, lying anterior to the hyoid bone, as

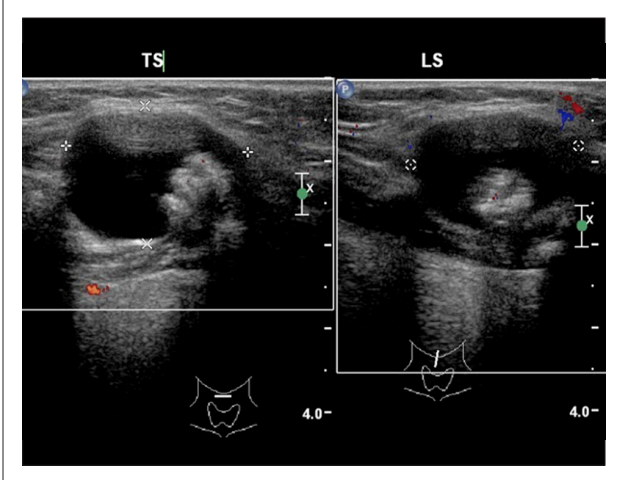

FIGURE 1: Sagittal B-mode sonar images of the right paramedian anterior neck mass, demonstrating the thyroglossal duct cyst (TDC) with intracystic postero-inferior echogenic nodule. Posterior acoustic shadowing indicates calcification of the nodule.

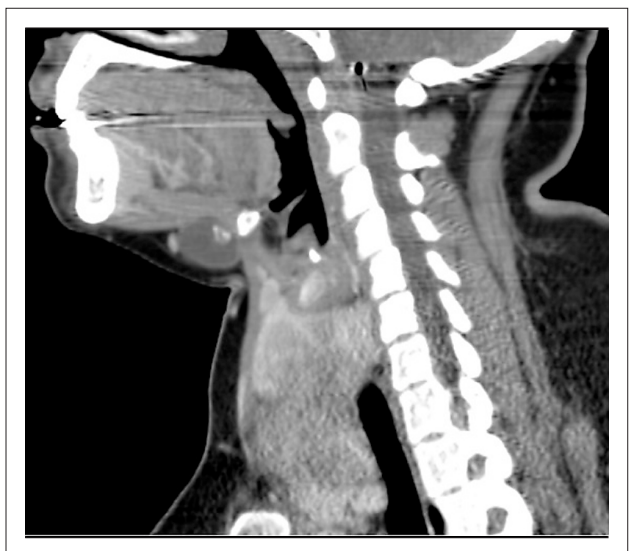

FIGURE 3: Sagittal paramidline computerised tomography (CT) image of the neck showing the relation of the thyroglossal duct cyst (TDC) to the hyoid bone.

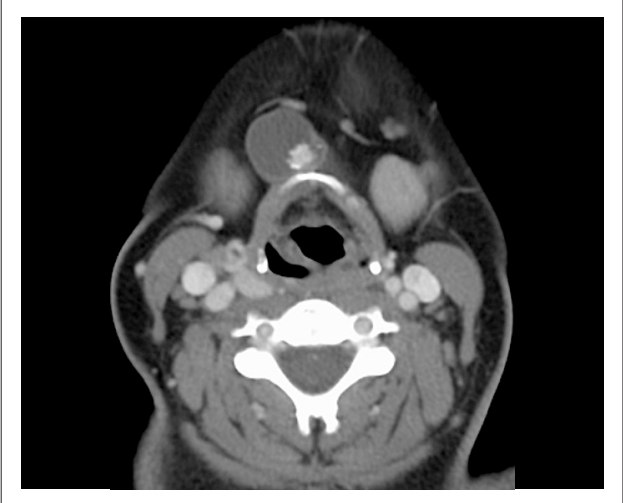

FIGURE 2: Axial computerised tomography (CT) scan image of the neck at the level of the hyoid bone, demonstrating the thyroglossal duct cyst (TDC) with a partly calcified, papillary, intracystic nodule.

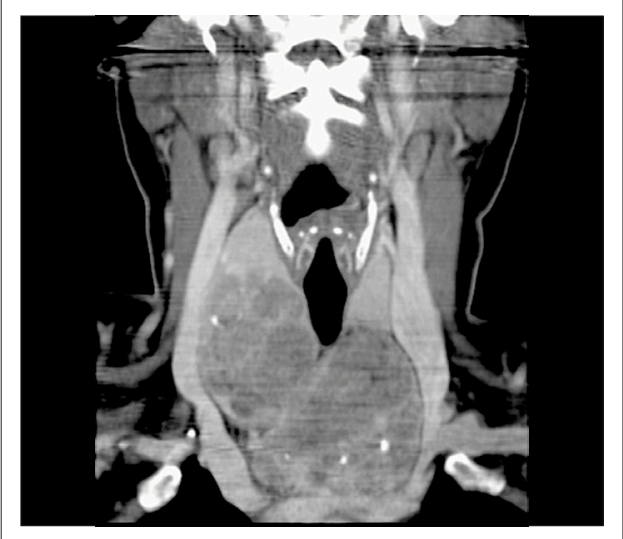

FIGURE 4: Coronal computerised tomography (CT) image of the anterior neck triangles demonstrating the multinodular thyromegaly. 
well as the enlarged thyroid gland. In Figure 4, the thyroid enlargement with a nodular texture, internal calcification and mass effect on the trachea and adjacent carotid sheath structures is evident.

The patient underwent extirpation of the cyst and the entire thyroid gland. Histological analysis confirmed that the cystic lesion was in fact a thyroglossal duct cyst (TDC) with intracystic papillary carcinoma. The thyroid gland, despite several reviews of the histological slides, failed to show any features of malignant change. There was, however, diffuse enlargement of the follicles with intervening areas of haemorrhage, calcification and fibrosis. There were no regional nodes showing evidence of malignant infiltrate. The final diagnosis was benign multinodular thyromegaly with TDC and a nodule containing papillary thyroid carcinoma.

\section{Discussion}

The embryology of the thyroid gland is complex. It is the first endocrine gland to develop in a fetus. Under the influence of fibroblast growth factor (FGF) signalling pathways, the thyroid diverticulum begins around day 24 as a proliferation of endodermal cells, at the midline pharyngeal floor between two structures (the tuberculum impar and copula), an area that is traditionally known as the foramen caecum. ${ }^{1}$ This ductlike invagination from the ventral pharyngeal endoderm is located between the first and second pharyngeal pouches. A tubular thyroglossal duct subsequently develops in a caudal direction along the midline, descending anterior to the hyoid bone and the airway. By the 7th week, two lateral anlages of the 4th and 5th branchial pouches develop into the ultimobranchial body which contains parafollicular c-cells. These are of neural crest origin and are later responsible for the secretion of calcitonin. These lateral bodies fuse with the midline descending thyroid primordium to form the thyroid gland. The thyroglossal duct atrophies by the 7th week to the 10th week, leaving a gland consisting of a median isthmus and two lateral lobes. In $50 \%$ of individuals, a pyramidal lobe, which is a residuum of the thyroglossal duct, is seen extending cranially from the isthmus.

Remnants of the thyroglossal duct anywhere along its track can result in ectopic thyroid tissue or a thyroglossal cyst. The sites of ectopic thyroid tissue and/or thyroglossal cyst formation are shown in Figure 5.

TDC is the most common congenital cystic mass of the neck, occurring in up to $90 \%$ of cases. ${ }^{1}$ Approximately $80 \%$ of these cysts are located at or below the level of the hyoid bone. ${ }^{2}$ Clinically, TDC presents as a painless paramedian swelling or anterior neck mass that moves on protruding the tongue or swallowing, owing to attachment to the hyoid bone.

Ultrasound of a TDC usually shows a midline anechoic mass in the typical locations described above, with a thin outer wall. There may be a variable internal echo within the cyst, depending on content, predominantly owing to proteinaceous material rather than infection or inflammation. ${ }^{3}$

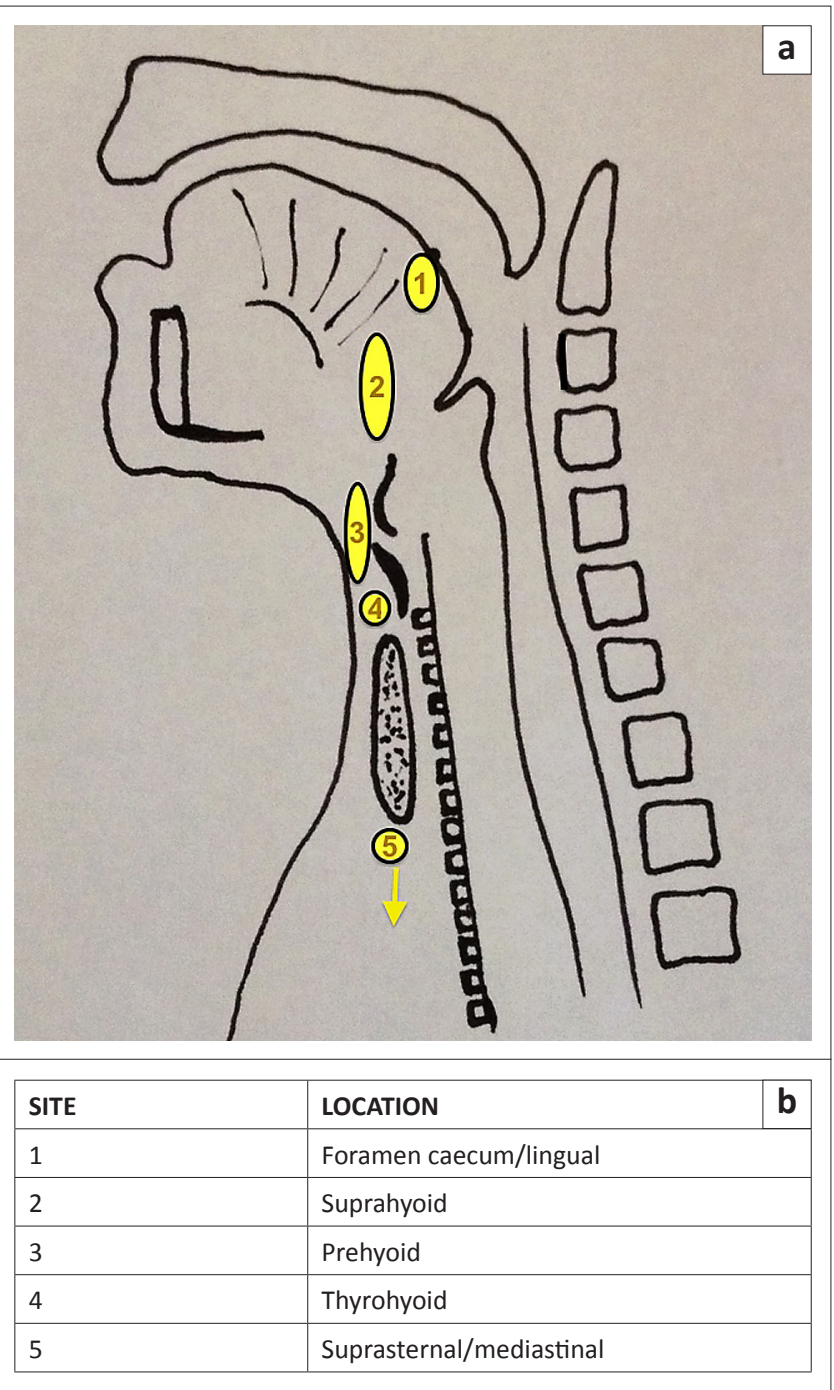

FIGURE 5: (a) Sagittal line diagram showing the common sites of ectopic thyroid rests or thyroglossal cyst formation; (b) Explanation of Figure $5 a$ sites and locations.

On CT scans, TDC appears as a well circumscribed, smoothwalled hypoattenuated mass along the course of embryologic thyroid migration (shown in Figure 5). Mean internal density measurements are typically less than 20 Hounsfield units. Increased density within a cyst may be the result of thicker, more viscous content, suggestive of prior infection. ${ }^{4}$ TDCs are usually unilocular with enhancing walls on post-contrast CT scans. Septation of a TDC may sometimes be observed. ${ }^{3}$

Thyroid scintigraphy using Technetium $99 \mathrm{~m}$ uptake scans is highly sensitive and specific in determining the presence of thyroid ectopia including TDC. Several cases of multifocal thyroid rests have been reported in the literature. Often, these rests of thyroid ectopia are the sole functional thyroid tissue, with no normal thyroid gland present.

Generally, TDCs have MRI features of a cyst with T1weighted reduced signal and corresponding T2-weighted shortening. An exception to the rule occurs in cases of high protein content, where T1-weighted hyperintensity is noted. Typically, there is no restricted diffusion within a TDC. Solid component with an intracystic nodule is well demonstrated 
on pre- and post-contrast MRI studies. Calcification shown on susceptibility weighted imaging (SWI) or gradient echo images should prompt suspicion of a malignant nodule within the TDC.

Associated malignancy within a TDC has been reported in $1 \%$ of cases. ${ }^{1}$ TDC carcinoma must be considered in the presence of a mural nodule and/or calcification on crosssectional imaging studies. ${ }^{2}$ Although more than $80 \%$ are of the papillary carcinoma type, there have been reports of all the malignant thyroid subtypes associated with TDC (except for medullary carcinoma which is related to parafollicular calcitonin-secreting cells). Nodal metastases are much less common in TDC-associated carcinoma than with primary neoplasms arising in the thyroid gland. ${ }^{3}$

The differential diagnoses of TDC are listed in Box 1 . Abscesses can occur anywhere in the neck and may track between neck spaces. MRI typically shows retricted diffusion of abscess content. Branchial cleft cysts, particularly second branchial cleft cysts, are located off-midline along the sternocleidomastoid muscle, posterior to the submandibular glands, and are often noted to insinuate between the carotid branches after the common carotid artery bifurcation. Dermoid and epidermoid cysts are easily differentiated from TDC by the presence of T1-weighted hyperintensity owing to fatty content and restricted diffusion on MRI studies respectively. $^{2}$

Plunging or diving ranulas show a thin cystic tract to the sublingual space; T2-weighted sequences are useful in demonstrating these tracts which usually pass around the mylohyoid muscle. Lymphatic malformations are detected earlier in life (usually before age 3 years), as these are congenital masses that may extend across cervical neck spaces and cause mass effect. Laryngocoeles arise from the laryngeal ventricle and extend superolaterally through the thyrohyoid membrane. These may be internal or external to the larynx and can become fluid-filled, in which case they are called saccular cysts. TDCs can also perforate the thyrohyoid membrane but are not intimately related to the laryngeal ventricle.

An important differential diagnosis is necrotic nodal metastasis from squamous carcinoma of the head and neck region in an adult patient presenting with a painless cystic cervical mass. Thymic cysts in the neck, akin to thyroglossal cysts, are remnants of the thymopharyngeal duct during a similar descent through the neck resulting in thymic rests. These foci are occult on thyroid uptake isotope imaging. ${ }^{2}$

Upon confirmation of a diagnosis of TDC-associated carcinoma, a surgical approach with a view to complete
BOX 1: Differential diagnoses for thyroglossal duct cysts. ${ }^{2}$

Abscess
Branchial cleft cyst
Cystic lymph node
Dermoid cyst
Epidermoid cyst
Plunging ranula
Lymphatic malformation
Laryngocoele
Squamous carcinoma
Thymic cyst

extirpation is mandatory. Simple cyst excision is inadequate and results in recurrence in $30 \%-60 \%$ of patients. ${ }^{5}$ The recommended standard surgical treatment in these patients is by the Sistrunk procedure which includes excision of the cyst, surrounding core of tissue around the TDC up to the foramen caecum and the central hyoid bone. A recurrence rate of less than $10 \%$ is noted following a Sistrunk procedure.

Treatment of TDC-associated carcinoma, in the absence of a native thyroid tumour, raises the question of thyroidectomy being indicated. It has been recommended that the thyroid gland should be removed along with the TDC carcinoma in cases where (1) the thyroid gland is nodular, with cold nodule on isotope uptake scan, (2) enlarged lymph nodes are present, or (3) a history of previous neck irradiation exists. ${ }^{6}$ Others recommend a more aggressive, albeit cautious, approach, to remove the thyroid gland along with the TDC carcinoma routinely at the time of Sistrunk operation. ${ }^{5}$

\section{Acknowledgements Competing interests}

The author declares that he has no financial or personal relationship(s) that may have inappropriately influenced him in writing this article.

\section{References}

1. Som PM, Smoker WR, Reidenberg JS, Bergemann AD, Hudgins PA, Laitman J. Embryology and anatomy of the neck. In: Som PM, Curtin HD, editors. Head and neck imaging. 5th edn. St Louis: Mosby, 2011; p. 2117-2163. http://dx.doi. org/10.1016/B978-0-323-05355-6.00034-3

2. Zander DA, Smoker WRK. Imaging of ectopic thyroid tissue and thyroglossal duct cysts. Radiographics. 2014;34:37-50. http://dx.doi.org/10.1148/rg.341135055

3. Koeller KK, Alamo L, Adair CF, Smirniotopoulos JG. From the archives of the AFIP. Congenital cystic masses of the neck: Radiologic-pathologic radiographics.19.1.g99ja06121

4. Branstetter BF, Weissman JL, Kennedy TL, Whitaker M. The CT appearance of thyroglossal duct carcinoma. AJNR. 2000;21:1547-1550.

5. Chrisolidou A, lliadou PK, Doumala E, et al. Thyroglossal duct cyst carcinomas: Is there a need for thyroidectomy? Hormones. 2013;12(4):522-528. http://dx.doi. org/10.14310/horm.2002.1440

6. Kazemi M, Assadi M, Kazemi AA, Ghazvini LA. Primary papillary carcinoma in a thyroglossal duct cyst. Hell J Nucl Med. 2006;9:39-40. 